\title{
Effect of Cooling Rates in Coiling Process on Microstructures and Mechanical Properties in AI-Bearing Hot-Rolled TRIP Steel
}

\author{
Xiao-Hui Wang ${ }^{1}$ · Jian Kang ${ }^{1}$ - Yun-Jie Li ${ }^{1}$. Guo Yuan ${ }^{1}$ - R. D. K. Misra ${ }^{2} \cdot$ Guo-Dong Wang $^{1}$
}

Received: 3 August 2018 / Revised: 8 October 2018 / Published online: 10 January 2019

(c) The Chinese Society for Metals (CSM) and Springer-Verlag GmbH Germany, part of Springer Nature 2019

\begin{abstract}
In this study, the effect of cooling rates on microstructures and mechanical properties in a Al-bearing hot-rolled transformation-induced plasticity steel was investigated. The experiments were carried out using hot simulation machine and hot rolling mill, where the samples were cooled at different cooling rates. The results showed that with the increase in cooling rates, film-like retained austenite gradually disappeared and only blocky retained austenite was retained at higher cooling rates. The volume fraction of retained austenite was $9-11 \%$ at cooling rates of $0.05-1{ }^{\circ} \mathrm{C} / \mathrm{s}$ and $4-6 \%$ at cooling rates of $5-10{ }^{\circ} \mathrm{C} / \mathrm{s}$. In addition, martensite/austenite island was observed because of the heterogeneous carbon distribution. The samples cooled at $0.05{ }^{\circ} \mathrm{C} / \mathrm{s}$ and $0.5^{\circ} \mathrm{C} / \mathrm{s}$ exhibited excellent mechanical properties, with tensile strengths of $712 \mathrm{MPa}$ and $726 \mathrm{MPa}$, total elongations of $42 \%$ and $36 \%$ and strength and ductility balances of $29.91 \mathrm{GPa} \%$ and $26.15 \mathrm{GPa} \%$, respectively. During plastic deformation, the instantaneous work hardening exponent of the sample cooled at $0.05{ }^{\circ} \mathrm{C} / \mathrm{s}$ increased continuously until it reached the maximum value, while the instantaneous work hardening exponent of the sample cooled at $0.5^{\circ} \mathrm{C} / \mathrm{s}$ remained stable.
\end{abstract}

Keywords Hot-rolled TRIP steels $\cdot$ Cooling rate $\cdot$ Microstructures $\cdot$ Mechanical properties $\cdot$ Work hardening behavior

\section{Introduction}

With the development of economy and safety in automotive industry, the transformation-induced plasticity (TRIP) steel has attracted much attention in recent years, due to its excellent combination of strength and ductility. The complex microstructures of TRIP steel are composed of ferrite, bainite, retained austenite (RA) and martensite [1]. The superior balance of tensile strength and total elongation is resulted from TRIP effect during tensile deformation, while TRIP effect arises from transformation of metastable retained austenite to martensite. Given that $\mathrm{Si}$ can reduce

Available online at http://link.springer.com/journal/40195

Guo Yuan

yuanguoral@sina.com

1 State Key Laboratory of Rolling and Automation, Northeastern University, Shenyang 110819, China

2 Laboratory for Excellence in Advanced Steel Research, Department of Metallurgical, Material and Biomedical Engineering, University of Texas at El Paso, El Paso, TX 79968, USA the surface quality in hot-rolled plates and galvanizing performance in cold-rolled plates, TRIP steels with partial $\mathrm{Si}$ substituted by some $\mathrm{Al}$ have been recently developed [2-4]. Zhu et al. [5] investigated the effect of $\mathrm{Al}$ and $\mathrm{Si}$ on bainite transformation, microstructures and mechanical properties of bainitic TRIP steel. Injeti et al. [6] elucidated the impact of $\mathrm{Al}$ content on microstructures and deformation mechanisms of TRIP steel. Huang et al. [7] studied the hot deformation behavior and processing maps of high $\mathrm{Al}$ low Si TRIP steel. Compared with the cold-rolled TRIP steels, hot-rolled TRIP steels exhibit many benefits in view of green development, such as short production process and low energy consumption. For partial substitution of Si by $\mathrm{Al}$, the microstructures and mechanical properties have been extensively studied in cold-rolled TRIP steels, but rarely studied in hot-rolled TRIP steels, especially in combination with coiling process [8-10].

The coiling process is an important part of production schedule for hot-rolled TRIP steels, where bainite transformation and carbon partitioning take place simultaneously in this process. The cooling rate in coiling process determines the time for bainite transformation and carbon partitioning and thus affects the final microstructures and 
Table 1 Chemical composition of the experimental steel (wt\%)

\begin{tabular}{lllllll}
\hline $\mathrm{C}$ & $\mathrm{Mn}$ & $\mathrm{Al}$ & $\mathrm{Si}$ & $\mathrm{S}$ & $\mathrm{P}$ & $\mathrm{Fe}$ \\
\hline 0.218 & 1.52 & 1.10 & 0.547 & 0.004 & 0.027 & $\mathrm{Bal}$. \\
\hline
\end{tabular}
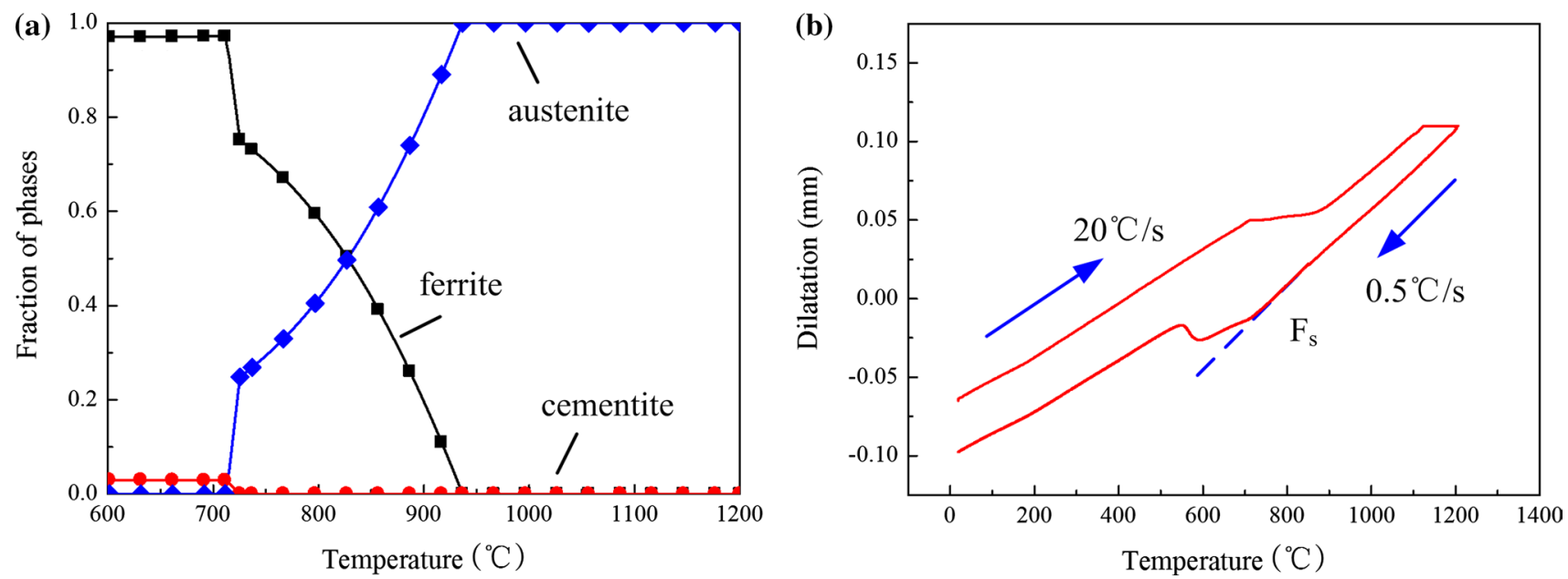

Fig. 1 Ferrite transformation temperature of the experimental steel in equilibrium and undercooled states: a volume fractions of phases versus temperature; $\mathbf{b}$ dilatation versus temperature

mechanical properties. Li et al. [11] investigated the effect of cooling rates on the relationship between microstructures and mechanical properties in hot-rolled Q\&P steels. However, there are few studies about the effect of cooling rates on microstructures and mechanical properties in hot-rolled TRIP steels, while bainite transformation and carbon partitioning in coiling process are not well understood $[12,13]$. The effect of cooling rates on retained austenite in hot-rolled TRIP steels continues to be fragmented and needs further study, such that the coiling process can be effectively utilized in online heat treatment for hot-rolled production.

In this study, the effect of cooling rates in coiling process on microstructures and mechanical properties in Al-bearing hot-rolled TRIP steel was investigated. In order to analyze the relationship between microstructures and mechanical properties, the effect of retained austenite on work hardening behavior was discussed. The research has many benefits to provide optical processing route for actual production of Al-containing hot-rolled TRIP steels.

\section{Experimental}

Table 1 shows the list of the chemical composition of experimental steel. The experimental steel was melt in vacuum induction furnace and then forged into billets with section dimensions of $90 \mathrm{~mm} \times 70 \mathrm{~mm}$. Figure 1 shows the ferrite transformation temperature of experimental steel in equilibrium and undercooled states. The $A_{\mathrm{e} 3}$ temperature

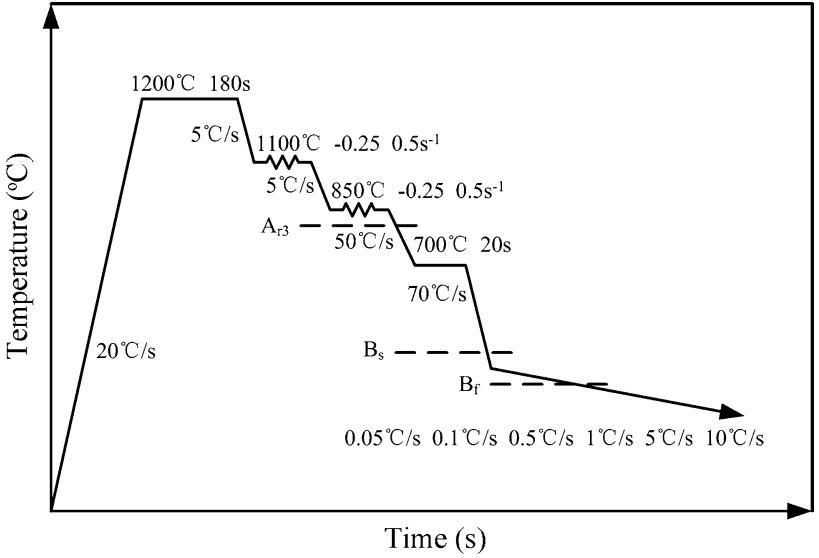

Fig. 2 Schematic diagram of processing route

in equilibrium state is $936{ }^{\circ} \mathrm{C}$ calculated by Thermo-Calc software, and the $A_{\mathrm{r} 3}$ temperature in undercooled state is $745^{\circ} \mathrm{C}$ according to static CCT curves.

Figure 2 illustrates the schematic diagram of processing route. The billets were reheated to $1200{ }^{\circ} \mathrm{C}$ for $2 \mathrm{~h}$ in boxtype resistance furnace, hot rolled to $12-\mathrm{mm}$-thick plates using $\phi 450$ hot rolling mill and then air cooled to room temperature. Cylindrical samples with $\phi 8 \mathrm{~mm} \times 15 \mathrm{~mm}$ were machined from the hot-rolled plates to conduct TMCP experiments in MMS 200 hot simulation machine. The experiments were conducted with compression deformation in recrystallization and unrecrystallization regions, to 
simulate the controlled rolling process with two stages [14, 15]. The samples were reheated to $1200^{\circ} \mathrm{C}$ for $180 \mathrm{~s}$ and subjected to deformation at $1100^{\circ} \mathrm{C}$, followed by cooling to $850{ }^{\circ} \mathrm{C}$ at the cooling rate of $5{ }^{\circ} \mathrm{C} / \mathrm{s}$. After deformation, the samples were subjected to intercritical holding at $700{ }^{\circ} \mathrm{C}$ for $20 \mathrm{~s}$, followed by cooling to bainite region at $400{ }^{\circ} \mathrm{C}$. The samples were cooled from bainite region to room temperature at different cooling rates of $0.05{ }^{\circ} \mathrm{C} / \mathrm{s}, 0.1^{\circ} \mathrm{C} / \mathrm{s}, 0.5^{\circ} \mathrm{C} / \mathrm{s}$, $1{ }^{\circ} \mathrm{C} / \mathrm{s}, 5^{\circ} \mathrm{C} / \mathrm{s}$ and $10{ }^{\circ} \mathrm{C} / \mathrm{s}$. To obtain mechanical properties of the experimental steel, three billets were hot rolled to 4-mm-thick plates using $\phi 450$ hot rolling mill and then cooled in furnace, asbestos and air. The cooling rates were close to $0.05{ }^{\circ} \mathrm{C} / \mathrm{s}, 0.5^{\circ} \mathrm{C} / \mathrm{s}$ and $5{ }^{\circ} \mathrm{C} / \mathrm{s}$, respectively.

The microstructural characterizations and elements distributions were studied using Jeol JXA-8530F electron probe microanalyzer (EPMA) equipped with energy-dispersive $\mathrm{X}$-ray spectrum (EDS) system at operating voltage of $20 \mathrm{kV}$, current of $2 \times 10^{-8} \mathrm{~A}$ and step size of $40 \mathrm{~nm}$. The phases characterizations were performed using Zeiss Ultra-55 field emission scanning electron microscopy (SEM) equipped with electron backscattered diffraction (EBSD) system which was used to distinguish the phases with different lattice structures. The fine structures were studied using TECNAI $\mathrm{G}^{2} 20$ field emission transmission electron microscopy (TEM) at operating voltage of $200 \mathrm{kV}$. For SEM observations and EPMA analyses, the samples were mechanically polished and etched with $4 \%$ nital solution for about $10 \mathrm{~s}$. The samples for EBSD analyses were electro-polished with electrolyte containing alcohol and perchloric acid in proportion of 7:1 at room temperature. The current was 1.0A and the time was $23 \mathrm{~s}$ for electro-polishing process. For TEM observations, the samples were first ground to $50 \mu \mathrm{m}$ in thickness and then electro-polished at $-20^{\circ} \mathrm{C}$ with a twinjet polisher.

The volume fraction and carbon content of retained austenite were measured using $\mathrm{D} / \max 2400 \mathrm{X}$-ray diffractometer (XRD) at operating voltage of $56 \mathrm{kV}$ and current of $182 \mathrm{~mA}$ with $\mathrm{Cu} K \alpha$ radiation at room temperature. The samples for XRD tests were electro-polished to remove the residual stress at the surfaces. The surfaces were scanned over $2 \theta$ range from $40^{\circ}$ to $101^{\circ}$ with step of $0.04^{\circ}$ s including austenite and ferrite diffraction peaks. The integrated intensity of austenite diffraction peaks $(200)_{\gamma},(220)_{\gamma}$ and $(311)_{\gamma}$ and that of ferrite diffraction peaks $(200)_{\alpha}$ and $(211)_{\alpha}$ were used to calculate the volume fraction of retained austenite by Jade version 6.5 software. The volume fraction of retained austenite was calculated using the equation in Ref. [16]. The carbon content was calculated using the equation in Ref. [17]. The lattice parameter of retained austenite was calculated using the equation in Ref. [18] based on austenite diffraction peaks $(200)_{\gamma},(220)_{\gamma}$ and (311) ${ }_{\gamma}$.

The tensile tests were conducted using Instron 4206 machine at room temperature with crosshead speed of
$3 \mathrm{~mm} / \mathrm{min}$. The hardness tests were conducted using $\mathrm{KB}$ 3000BURZ-SA hardness tester at a load of HV10. The samples for tensile tests were prepared along the rolling direction with dimension of $25 \mathrm{~mm}$ in gauge length, $10 \mathrm{~mm}$ in width and $4 \mathrm{~mm}$ in thickness. The tensile strength, yield strength and total elongation were average of three results for each plate. The hardness of the experimental steel was obtained based on the average of ten results for each sample. The instantaneous work hardening exponent was calculated using the following equation [19]:

$n=\frac{\mathrm{d}(\ln \sigma)}{\mathrm{d}(\ln \varepsilon)}$

where $n$ is the instantaneous work hardening exponent and $\sigma$ and $\varepsilon$ are the true stress and true strain, respectively.

\section{Results and Discussion}

\subsection{Effect of Cooling Rates on Microstructures}

Figure 3 shows the microstructures of the experimental steel cooled from $400{ }^{\circ} \mathrm{C}$ at different cooling rates. There existed obvious differences in microstructures between the samples cooled at higher and at lower cooling rates. In Fig. 3a-d, when the cooling rate is lower than $1{ }^{\circ} \mathrm{C} / \mathrm{s}$, the microstructures are comprised of polygonal ferrite, bainitic ferrite and retained austenite. In comparison, when the cooling rate is higher than $5{ }^{\circ} \mathrm{C} / \mathrm{s}$, the microstructures consist of polygonal ferrite, martensite and retained austenite, as shown in Fig. 3e, f.

The cooling rate had significant effects on microstructures of the experimental steel. With the increase in cooling rates, bainite ferrite and retained austenite were substituted by martensite. From SEM images, bainitic laths together with film-like retained austenite made up prior austenite, which had grain size less than $20 \mu \mathrm{m}$. Because the formation of cementite was inhibited by $\mathrm{Al}$ and $\mathrm{Si}$, bainitic ferrite was also one type of carbon-free bainite. Akbary et al. [20] suggested that carbon-free bainite was beneficial to obtaining larger amount of retained austenite. In addition, polygonal ferrite was located at the grain boundaries of prior austenite and its grain size was less than $10 \mu \mathrm{m}$. It was noticed that some structures were located at polygonal ferrite grain boundaries at lower cooling rates, as marked with the red circle. These structures were probably martensite/austenite island or retained austenite, which depended on their grain size and carbon distribution. From the SEM images, martensite/austenite island and retained austenite were hardly identified, because they had similar phase morphology with smooth surface. In general, the structures with larger size 

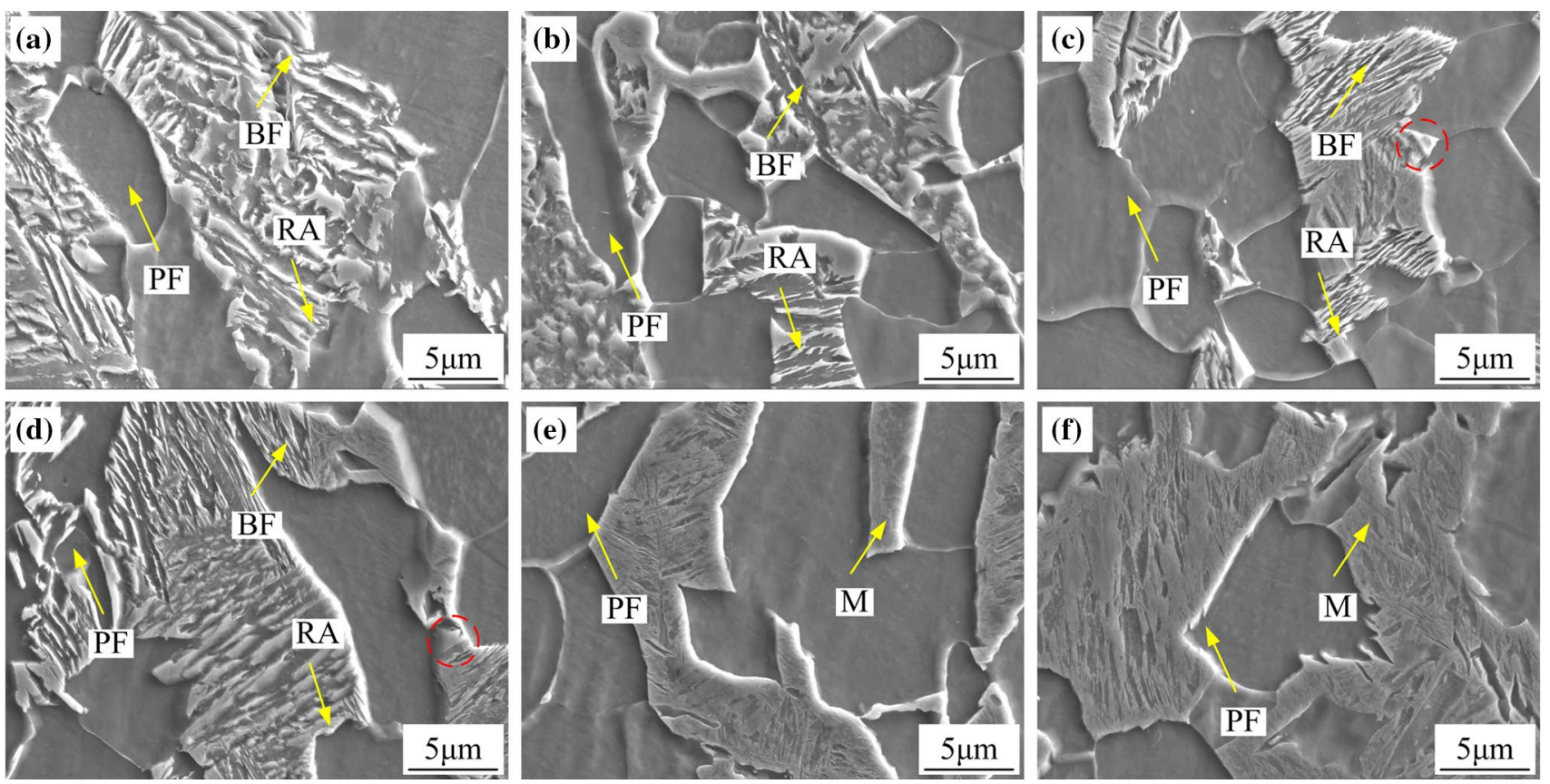

Fig. 3 Microstructures of the experimental steel cooled from $400{ }^{\circ} \mathrm{C}$ at different cooling rates: a $0.05{ }^{\circ} \mathrm{C} / \mathrm{s} ; \mathbf{b ~} 0.1{ }^{\circ} \mathrm{C} / \mathrm{s} ; \mathbf{c} 0.5{ }^{\circ} \mathrm{C} / \mathrm{s} ; \mathbf{d} 1{ }^{\circ} \mathrm{C} / \mathrm{s} ; \mathbf{e}$ $5{ }^{\circ} \mathrm{C} / \mathrm{s} ; \mathrm{f} 10^{\circ} \mathrm{C} / \mathrm{s}$. PF is polygonal ferrite, $\mathrm{BF}$ is bainitic ferrite, $\mathrm{RA}$ is retained austenite and $\mathrm{M}$ is martensite

were martensite/austenite island, whereas those with smaller size were retained austenite. When the carbon diffused from proeutectoid ferrite to residual austenite, they usually concentrated at the grain boundaries of residual austenite. For residual austenite with larger grain size, the internal part of residual austenite transformed to martensite, due to its poor carbon concentration. As a consequence, martensite/austenite island formed from residual austenite with heterogeneous carbon distribution. However, residual austenite with smaller grain size was stable and retained at room temperature. For better characterization of these structures, martensite/austenite island and retained austenite were further studied with TEM observations and EBSD analyses in the following part.

Figure 4 shows the carbon distribution of the experimental steel cooled from $400{ }^{\circ} \mathrm{C}$ at different cooling rates. Because carbon partitioning had an important influence on the stability of retained austenite, the carbon distribution of the experimental steel was essential to be observed in order to analyze the effect of cooling rates on microstructures. Since carbon content was the main factor that governed chemical stability of retained austenite and the distribution of $\mathrm{Mn}, \mathrm{Al}$ and $\mathrm{Si}$ was relatively homogeneous, only carbon distribution was discussed here. In Fig. 3a, b, at lower cooling rates of $0.5{ }^{\circ} \mathrm{C} / \mathrm{s}$ and $1{ }^{\circ} \mathrm{C} / \mathrm{s}$, carbon element was enriched in film-like and blocky retained austenite. In contrast, at higher cooling rates of 5 and $10{ }^{\circ} \mathrm{C} / \mathrm{s}$, carbon element was enriched in martensite, as shown in Fig. 3c, d.

With the increase in cooling rates, the carbon distribution changed obviously. The carbon was enriched in film-like and blocky retained austenite at lower cooling rates, while it was enriched in martensite when cooling rate exceeded $5{ }^{\circ} \mathrm{C} / \mathrm{s}$. The reason is that there was no adequate time for bainite transformation and carbon partitioning at higher cooling rates. Therefore, bainitic ferrite and film-like retained austenite were not obtained. It was known that the carbon enrichment in film-like retained austenite was attributed to carbon diffusion from bainitic ferrite to retained austenite during bainite transformation, whereas the carbon enrichment in martensite was ascribed to carbon migration from proeutectoid ferrite to residual austenite during ferrite transformation [21]. In addition, the carbon distribution in film-like and blocky retained austenite had no much relation with cooling rates, but the carbon distribution in martensite becomes less homogeneous. There was more carbon element enriched at internal part of martensite at the cooling rate of $5{ }^{\circ} \mathrm{C} / \mathrm{s}$, in contrast to the cooling rate of $10{ }^{\circ} \mathrm{C} / \mathrm{s}$. It was indicated that the cooling rate had no effects on the carbon distribution in film-like and blocky-type retained austenite, but it influenced the carbon distribution in martensite.

Figure 5 shows the EBSD images of the experimental steel cooled from $400{ }^{\circ} \mathrm{C}$ at different cooling rates. From the EBSD analyses, the morphology and distribution of retained austenite were readily observed. Given that the samples cooled at $0.05{ }^{\circ} \mathrm{C} / \mathrm{s}$ and $0.1{ }^{\circ} \mathrm{C} / \mathrm{s}$ had adequate time for carbon partitioning, the samples cooled at $0.5-10{ }^{\circ} \mathrm{C} / \mathrm{s}$ were selected to be observed for EBSD analyses. In Fig. 5a, $\mathrm{b}$, at lower cooling rates of $0.5{ }^{\circ} \mathrm{C} / \mathrm{s}$ and $1{ }^{\circ} \mathrm{C} / \mathrm{s}$, film-like retained austenite is located between bainitic laths and 

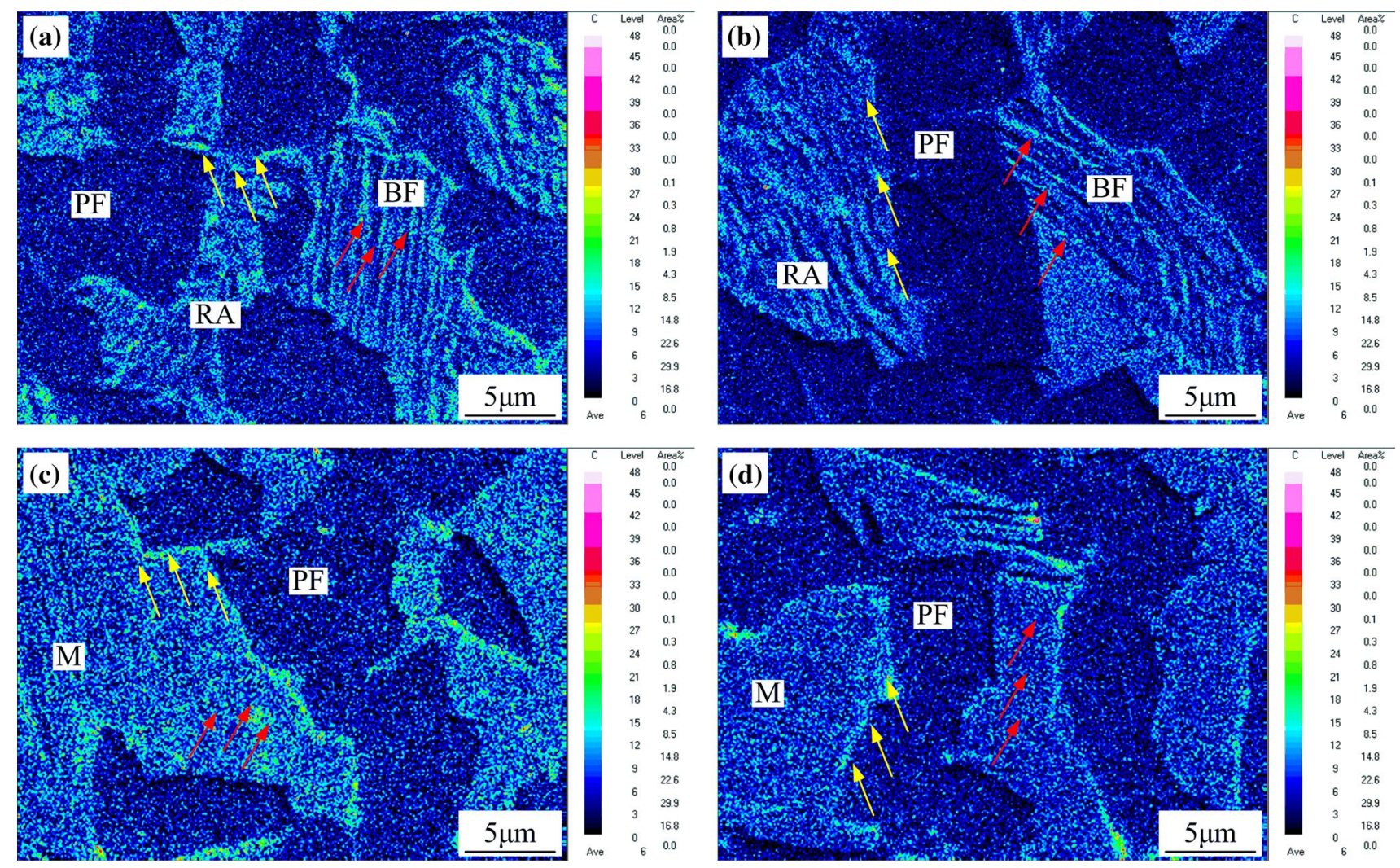

$\begin{array}{cc}\text { Cevel Area\% } \\ 48 & 0.0 \\ 45 & 0.0 \\ 45 & 0.0 \\ 42 & 0.0 \\ 39 & 0.0 \\ 36 & 0.0 \\ 33 & 0.0 \\ 33 & 0.0 \\ 30 & 0.1 \\ 27 & 0.3 \\ 24 & 0.3 \\ 21 & 0.8 \\ 18 & 1.9 \\ 18 & 4.3 \\ 15 & 8.5 \\ 12 & 14.8 \\ 9 & 22.6 \\ 6 & 29.9 \\ 3 & 29.8 \\ 0 & 16.8 \\ { }_{6} & 0.0\end{array}$

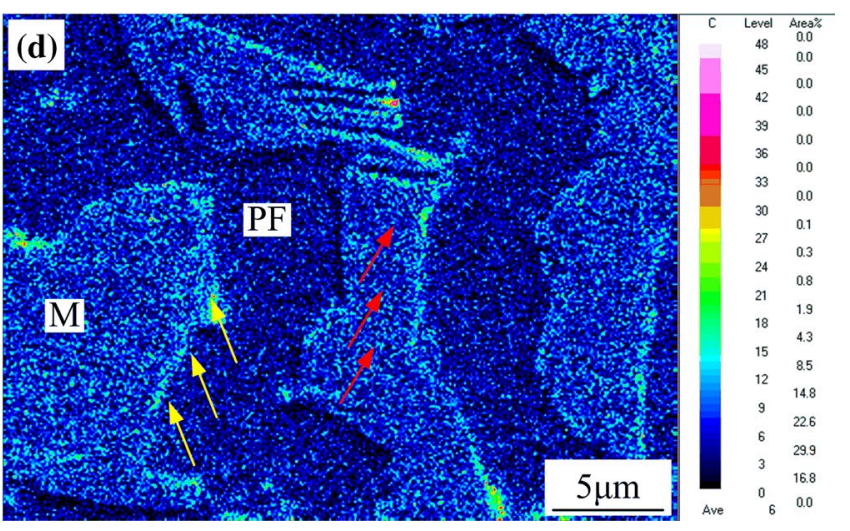

Fig. 4 Carbon distribution of the experimental steel cooled from $400{ }^{\circ} \mathrm{C}$ at different cooling rates: a $0.5{ }^{\circ} \mathrm{C} / \mathrm{s} ; \mathbf{b} 1{ }^{\circ} \mathrm{C} / \mathrm{s} ; \mathbf{c} 5{ }^{\circ} \mathrm{C} / \mathrm{s} ; \mathbf{d} 10{ }^{\circ} \mathrm{C} / \mathrm{s}$. $\mathrm{PF}$ is polygonal ferrite, $\mathrm{BF}$ is bainitic ferrite, $\mathrm{RA}$ is retained austenite and $\mathrm{M}$ is martensite

blocky retained austenite is distributed around polygonal ferrite. In comparison, at higher cooling rates of $5{ }^{\circ} \mathrm{C} / \mathrm{s}$ and $10{ }^{\circ} \mathrm{C} / \mathrm{s}$, film-like retained austenite disappears in microstructures and only blocky retained austenite is retained, as shown in Fig. 5c, d.

The cooling rate played an important role in the nature of retained austenite. With the increase in cooling rates, filmlike retained austenite was not retained in microstructures and only blocky retained austenite was present. These results were in agreement with EPMA analyses. It was indicated that film-like retained austenite was affected by cooling rates, whereas blocky retained austenite had no relation with cooling rates. There was adequate time for carbon partitioning during bainite transformation at lower cooling rates; thus, film-like retained austenite was obtained. In comparison, blocky retained austenite mainly depended on carbon diffusion from proeutectoid ferrite during ferrite transformation, so it was retained at higher cooling rates.

Figures 6, 7 and 8 show the TEM images of the experimental steel cooled from $400{ }^{\circ} \mathrm{C}$ at cooling rates of $0.05{ }^{\circ} \mathrm{C} / \mathrm{s}, 5{ }^{\circ} \mathrm{C} / \mathrm{s}$ and $0.5{ }^{\circ} \mathrm{C} / \mathrm{s}$, respectively. Two kinds of retained austenite and martensite/austenite island were present in the samples cooled at lower cooling rates. However, only blocky retained austenite and martensite were present in the samples cooled at higher cooling rates. In Fig. 6a-c, film-like retained austenite with width of $150-250 \mathrm{~nm}$ is observed between bainitic lath in the sample cooled at $0.05{ }^{\circ} \mathrm{C} / \mathrm{s}$. In comparison, blocky retained austenite with dimension of $550-650 \mathrm{~nm}$ is observed around polygonal ferrite, as shown in Fig. 6d-f. In Fig. 7, martensite with grain size over $1 \mu \mathrm{m}$ is observed between ferrite grains in the sample cooled at $5{ }^{\circ} \mathrm{C} / \mathrm{s}$. In contrast, martensite/austenite island with grain size below $2 \mu \mathrm{m}$ is observed at polygonal ferrite grain boundaries in the sample cooled at $0.5^{\circ} \mathrm{C} / \mathrm{s}$, as shown in Fig. 8.

With the variation of cooling rates, the final microstructures transformed from residual austenite were different in coiling process. The presence of film-like retained austenite was attributed to bainite transformation and carbon partitioning; thus, film-type retained austenite was observed in the samples only cooled at lower cooling rates [22]. However, the formation of blocky retained austenite was ascribed to carbon diffusion from proeutectoid ferrite, so blocky retained austenite was observed in the samples cooled at all cooling rates [23]. Because of the inadequate time for bainite transformation, the presence of martensite was available in the samples cooled at higher cooling rates. It was interesting that martensite/austenite island was observed at polygonal 

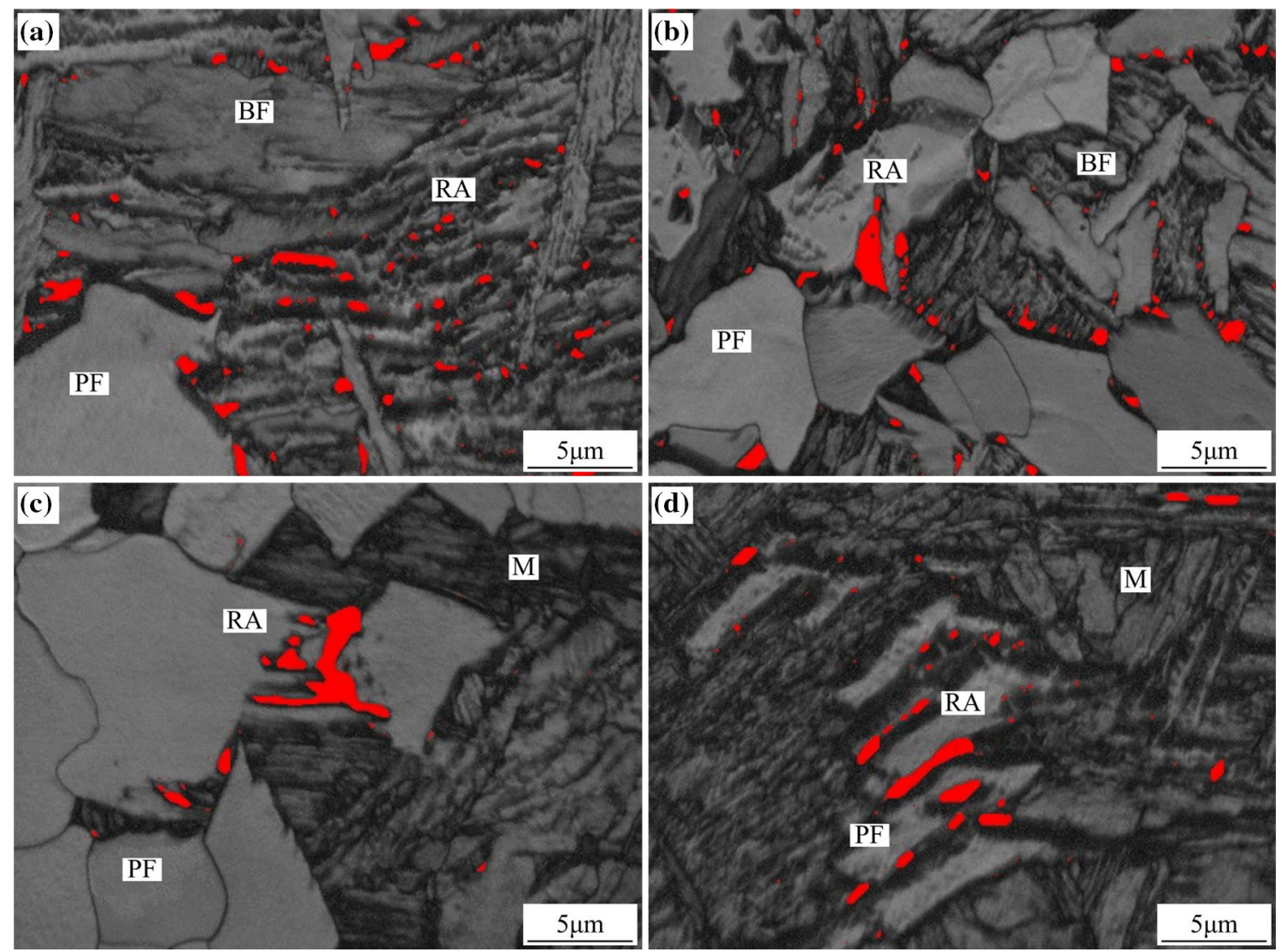

Fig. 5 EBSD images of the experimental steel cooled from $400{ }^{\circ} \mathrm{C}$ at different cooling rates: a $0.5{ }^{\circ} \mathrm{C} / \mathrm{s} ; \mathbf{b} 1{ }^{\circ} \mathrm{C} / \mathrm{s} ;$ c $5{ }^{\circ} \mathrm{C} / \mathrm{s} ; \mathbf{d} 10{ }^{\circ} \mathrm{C} / \mathrm{s}$. $\mathrm{PF}$ is polygonal ferrite, $\mathrm{BF}$ is bainitic ferrite, $\mathrm{RA}$ is retained austenite and $\mathrm{M}$ is martensite

ferrite grain boundaries. The residual austenite received carbon element from adjacent ferrite; consequently, it was enriched with carbon element. In some cases, the carbon distribution in residual austenite was heterogeneous, in spite of high diffusion rate of carbon element at higher temperature [24]. The region close to polygonal ferrite was expected to have more carbon enrichment, whereas the region far from polygonal ferrite had less carbon enrichment. As a result, the internal part of residual austenite transformed into martensite and the rest part was retained at room temperature. It was reported that some residual austenite with specific grain size transformed into twin martensite, because the carbon content was relatively high but it could not retain residual austenite [25]. The majority of blocky residual austenite with high carbon content was retained, for the reason that there was little twin martensite in microstructures.

Figure 9 shows the volume fraction and carbon content of retained austenite. In Fig. 9a, the samples have remarkable austenite diffraction peaks at lower cooling rates and slight austenite diffraction peaks at higher cooling rates. In Fig. 9c, the volume fraction of retained austenite is $9-11 \%$ at lower cooling rates and $4-6 \%$ at higher cooling rates. It was obvious that the volume fraction of retained austenite suddenly decreased when the cooling rate exceeded $5{ }^{\circ} \mathrm{C} / \mathrm{s}$. The reason was that at lower cooling rates, there was adequate time for bainite transformation and carbon partitioning, whereas most of the carbon element was restricted in supersaturated martensite at higher cooling rates. The maximum volume fraction of retained austenite was $10.71 \%$ when the cooling rate was $0.1{ }^{\circ} \mathrm{C} / \mathrm{s}$. The lower cooling rate resulted in slight tempering for retained austenite, and the higher cooling rate led to inadequate time for carbon partitioning. As a consequence, the extreme cooling rate no matter too slow or too high was not favorable for retained austenite. It was interesting that the change in volume fraction of retained austenite was not obvious when the cooling rate increased from 0.05 to $1{ }^{\circ} \mathrm{C} / \mathrm{s}$. Thomas et al. [26] found that the coiling process provided adequate time for carbon partitioning. In our work, the cooling rate less than $1{ }^{\circ} \mathrm{C} / \mathrm{s}$ ensured adequate time for carbon partitioning, so a large amount of retained austenite was obtained at room temperature. The microstructural characterizations show that the cooling rate induced no differences in microstructural constituents, especially in retained austenite at lower cooling rates, because the compressive deformation probably enhanced carbon partitioning during bainite transformation. The rolling deformation 

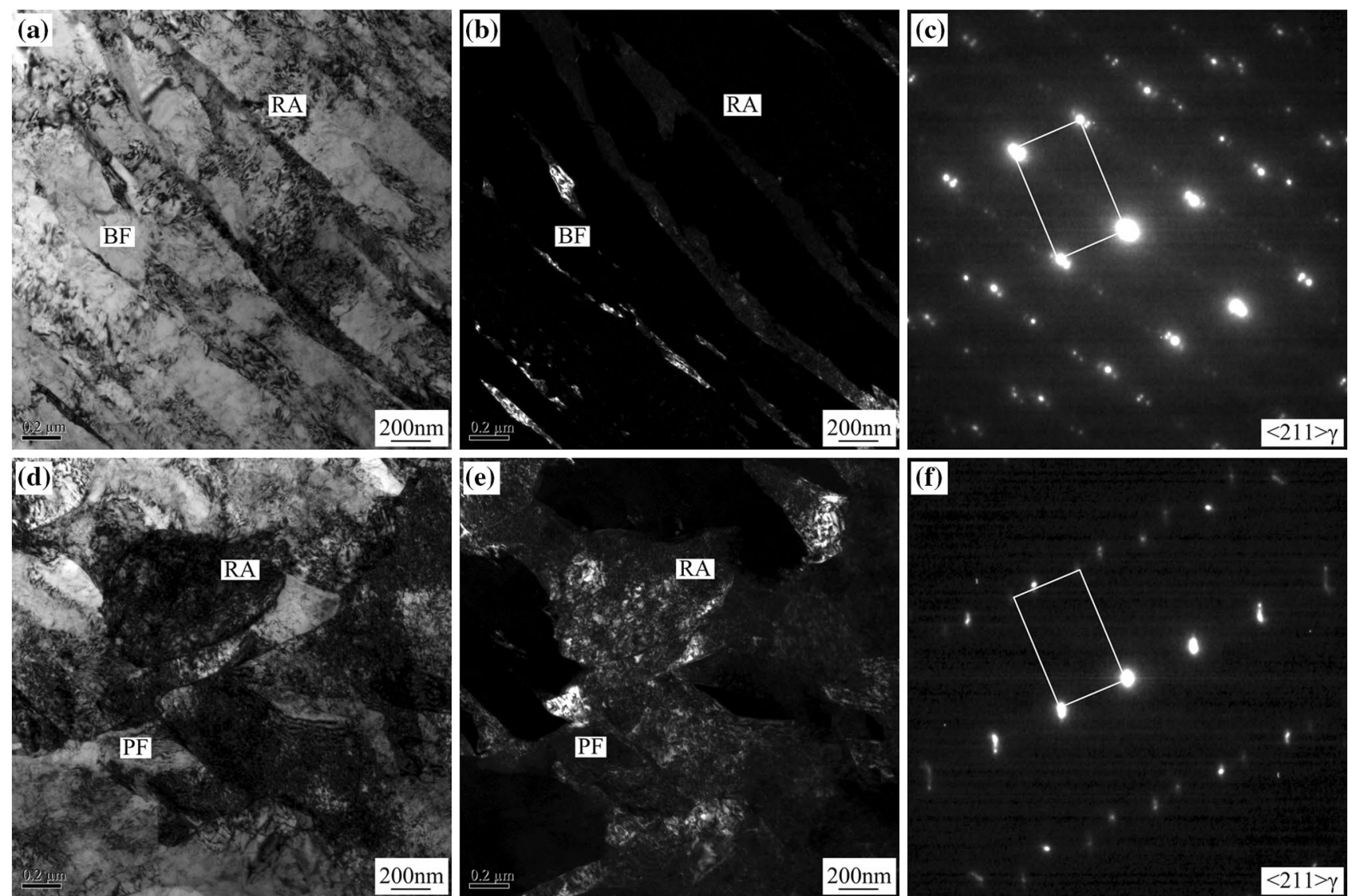

Fig. 6 TEM images of the experimental steel cooled from $400{ }^{\circ} \mathrm{C}$ at the cooling rate of $0.05{ }^{\circ} \mathrm{C} / \mathrm{s}$ : a film-like retained austenite in bright field; b film-like retained austenite in dark field; $\mathbf{c}$ film-like retained austenite in SAED pattern; e blocky retained austenite in bright field; f blocky retained austenite in dark field; $\mathbf{g}$ blocky retained austenite in SAED pattern. $\mathrm{PF}$ is polygonal ferrite, $\mathrm{BF}$ is bainitic ferrite and $\mathrm{RA}$ is retained austenite
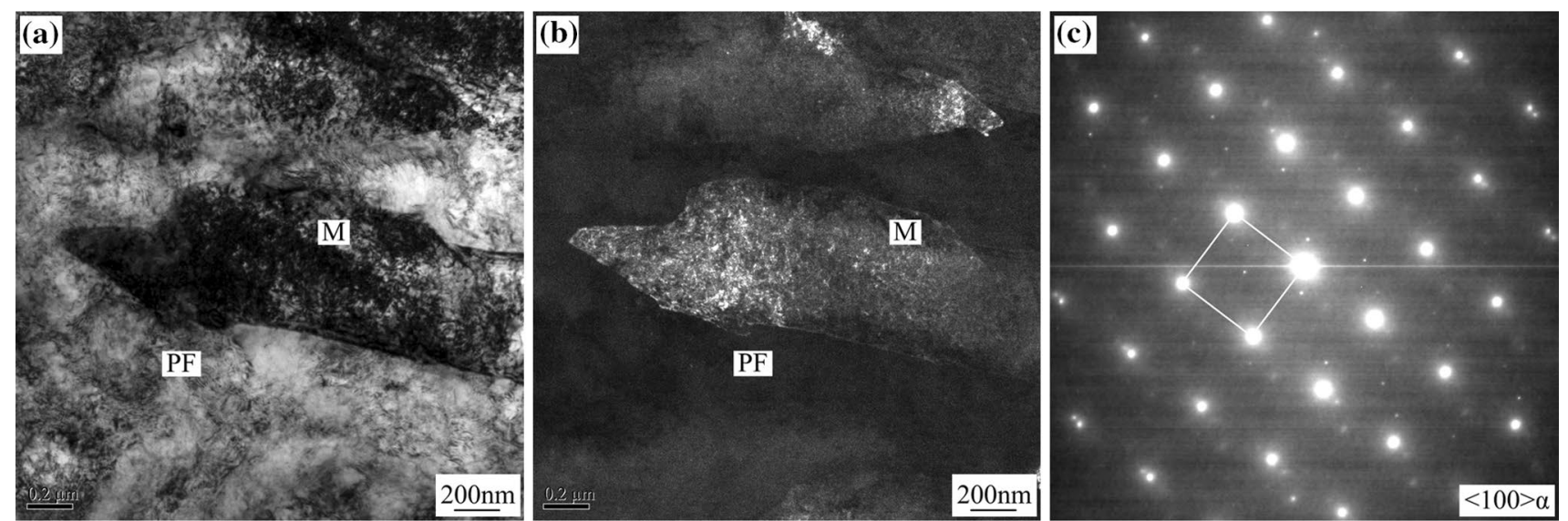

Fig. 7 TEM images of the experimental steel cooled from $400{ }^{\circ} \mathrm{C}$ at the cooling rate of $5{ }^{\circ} \mathrm{C} / \mathrm{s}$ : a martensite in bright field; $\mathbf{b}$ martensite in dark field; $\mathbf{c}$ martensite in SAED pattern. PF is polygonal ferrite and $\mathrm{M}$ is martensite

also promoted carbon partitioning for retained austenite and broadened process window for cooling rates, which provided many benefits for industrial production.
Another significant aspect to be discussed was carbon content of retained austenite. In Fig. 9b, austenite diffraction peak $(200)_{\gamma}$ was used to calculate carbon content of 

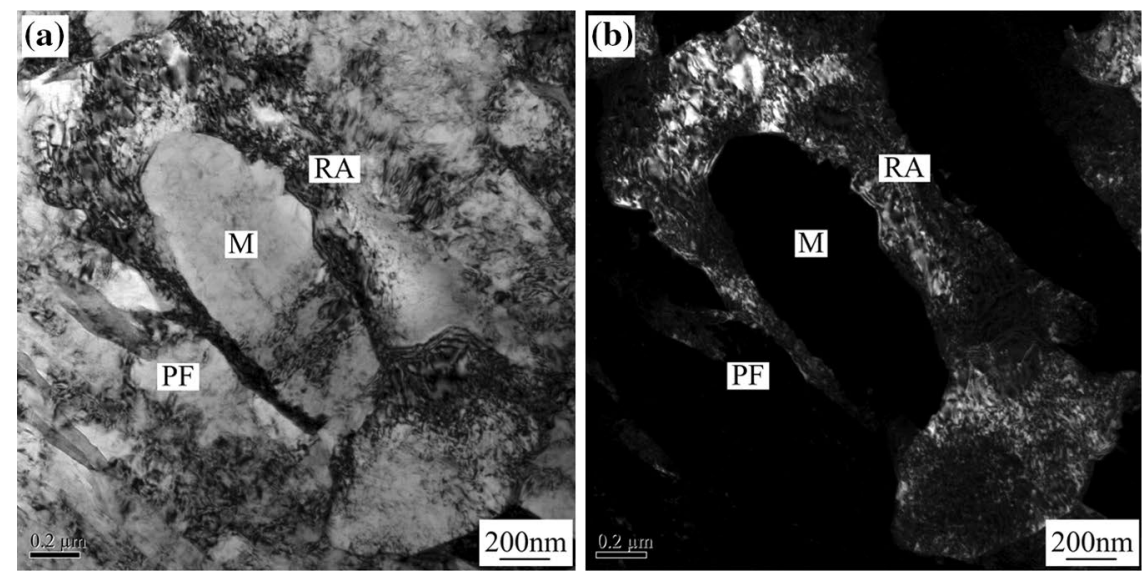

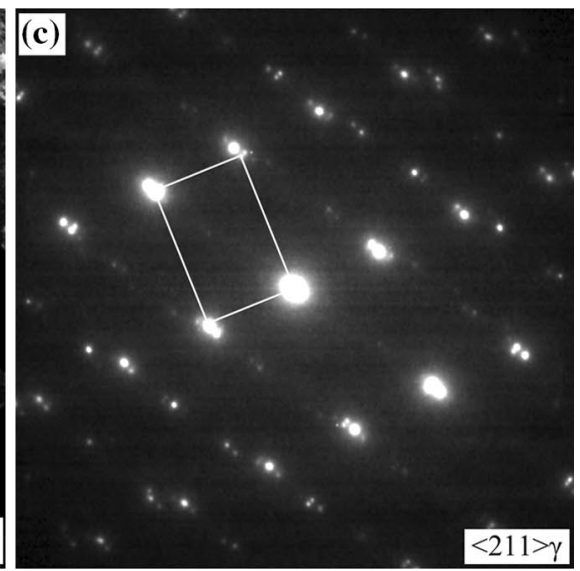

tenite island in SAED pattern. PF is polygonal ferrite, RA is retained austenite and $\mathrm{M}$ is martensite
Fig. 8 TEM images of the experimental steel cooled from $400{ }^{\circ} \mathrm{C}$ at the cooling rate of $0.5{ }^{\circ} \mathrm{C} / \mathrm{s}$ : a martensite/austenite island in bright field; b martensite/austenite island in dark field; $\mathbf{c}$ martensite/aus-
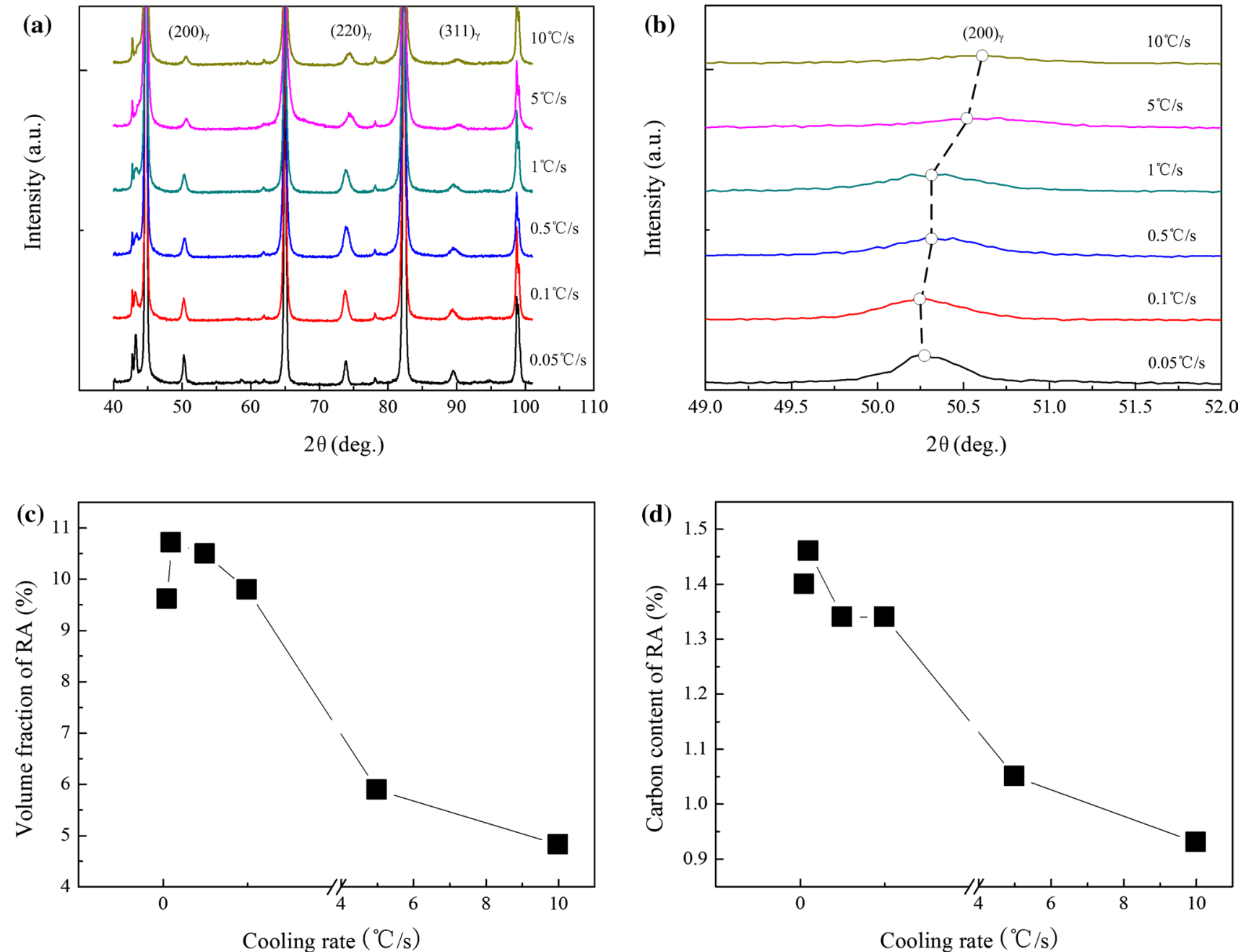

Fig. 9 Volume fraction and carbon content of retained austenite at different cooling rates: a XRD curves; $\mathbf{b}$ austenite diffraction peaks; $\mathbf{c}$ the volume fraction of retained austenite; $\mathbf{d}$ the carbon content of retained austenite 
retained austenite and there were some differences in austenite diffraction peaks at different cooling rates. In Fig. 9d, carbon content of retained austenite varied in $1.3-1.5 \%$ at lower cooling rates and $0.9-1.1 \%$ at higher cooling rates. It was clear that the carbon content of retained austenite suddenly decreased when the cooling rate exceeded $5{ }^{\circ} \mathrm{C} / \mathrm{s}$. The carbon content of retained austenite reached the maximum value of $1.46 \%$ at the cooling rate of $0.1{ }^{\circ} \mathrm{C} / \mathrm{s}$ and then decreased with the increase in cooling rates. The carbon content of film-like retained austenite varied with the cooling rates, because the time for carbon partitioning was different in coiling process. The carbon content of blocky retained austenite was expected to be high at different cooling rates, as sufficient carbon element diffused from proeutectoid ferrite to these structures. It was indicated that the mean carbon content of retained austenite depended on the proportion of film-like and blocky retained austenite, as well as their own carbon content.
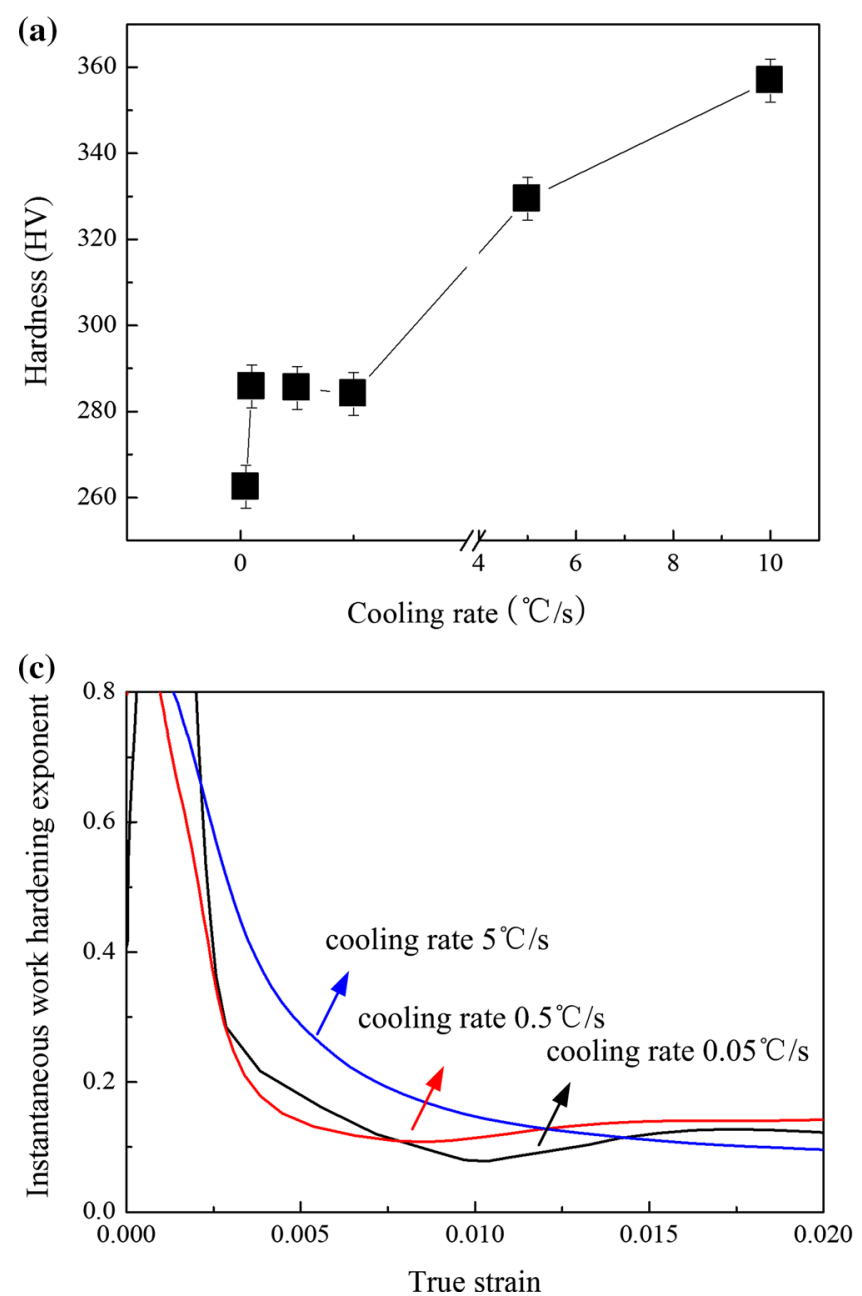

Fig. 10 Hardness and mechanical properties of the experimental steel at different cooling rates: a hardness of experimental steel; $\mathbf{b}$ engineering strain and engineering stress curves; $\mathbf{c}$ instantaneous work

\subsection{Effect of Cooling Rates on Mechanical Properties}

Figure 10 shows the hardness and mechanical properties of the experimental steel cooled from $400{ }^{\circ} \mathrm{C}$ at different cooling rates. The complex microstructures of experimental steel were expected to exhibit excellent mechanical properties. In general, bainitic ferrite and martensite provided strength and polygonal ferrite ensured ductility, whereas retained austenite was the critical factor in work hardening behavior. Besides, polygonal ferrite accommodated strain distribution between different phases during tensile deformation and enriched carbon element in residual austenite during ferrite transformation. It was reported that blocky retained austenite had appropriate stability and experienced TRIP effect at work hardening stage [22]. However, film-like retained austenite was more stable than blocky retained austenite and transformed to
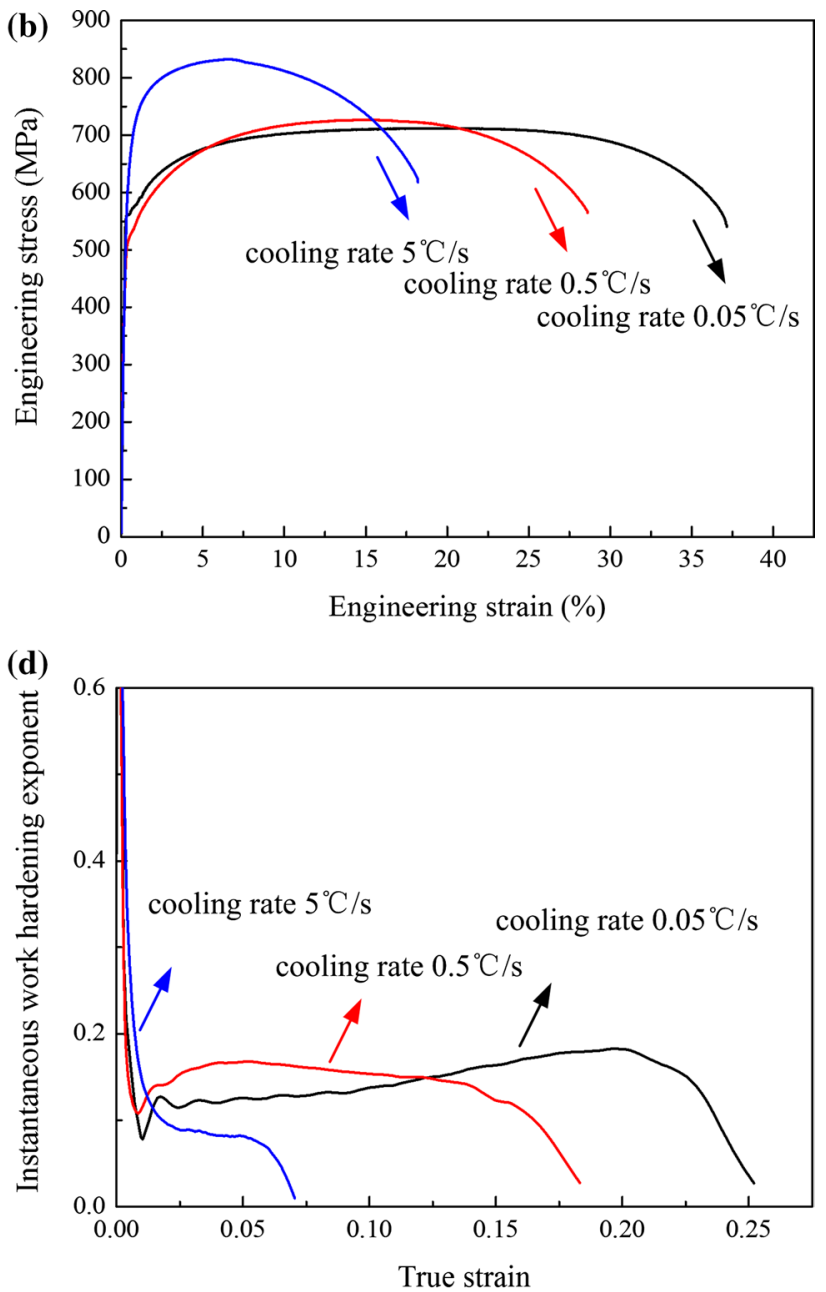

hardening exponent during dislocations interaction; $\mathbf{d}$ instantaneous work hardening exponent during plastic deformation 
martensite at large strain [23]. The martensite contained higher-density dislocations and retarded slide of dislocations in plastic deformation. In addition, martensite/austenite island was beneficial to obtaining high total elongation, for the reason that it changed the direction of crack propagation and delayed occurrence of fracture. Zhao et al. [27] proposed that martensite/austenite island changed the direction of crack propagation and improved the ductility of pipeline steels. Now that the hardness of experimental steel was reflected in microstructural constituents, the hardness tests were conducted in this research. In Fig. 10a, the hardness of the experimental steel varies in the range of 260-290 HV at lower cooling rates and 320-360 HV at higher cooling rates. The sample cooled at $10{ }^{\circ} \mathrm{C} / \mathrm{s}$ had the maximum hardness of $357 \mathrm{HV}$, due to the presence of martensite in microstructures. However, the sample cooled at $0.05^{\circ} \mathrm{C} / \mathrm{s}$ had the minimum hardness of $262 \mathrm{HV}$, because of the tempering of retained austenite. The cooling rates influenced microstructural constituents, and the tempering of retained austenite occurred at lower cooling rates. Therefore, the hardness of the experimental steel depended on the cooling rate obviously.

In order to investigate the mechanical properties of the experimental steel at different cooling rates, some necessary hot rolling experiments were conducted in this research. Three plates were hot rolled in controlled rolling process with a total reduction of $90 \%$. In addition, the plates were cooled in furnace, asbestos and air, respectively, to simulate cooling rates of $0.05{ }^{\circ} \mathrm{C} / \mathrm{s}, 0.5^{\circ} \mathrm{C} / \mathrm{s}$ and $5{ }^{\circ} \mathrm{C} / \mathrm{s}$. In Fig. 10b, from engineering stress and engineering strain curves, the mechanical properties of the experimental steel exhibit much difference. The samples cooled at $0.05{ }^{\circ} \mathrm{C} / \mathrm{s}$ and $0.5{ }^{\circ} \mathrm{C} / \mathrm{s}$ had relatively similar mechanical properties, with tensile strength of $712 \mathrm{MPa}$ and $726 \mathrm{MPa}$, total elongation of $42 \%$ and $36 \%$ and strength ductility balance of $29.91 \mathrm{GPa} \%$ and $26.15 \mathrm{GPa} \%$, respectively. Compared with the samples cooled at lower cooling rates, the sample cooled at $5{ }^{\circ} \mathrm{C} / \mathrm{s}$ had different mechanical properties, with tensile strength of $832 \mathrm{MPa}$, total elongation of $24 \%$ and strength ductility balance of $19.96 \mathrm{GPa} \%$, respectively. It was clear that the samples cooled at lower cooling rates exhibited higher total elongation together with superior combination of strength and ductility, whereas the sample cooled at higher cooling rates exhibited higher tensile strength. The volume fractions of retained austenite were $18.48 \%, 15.77 \%$ and $5.17 \%$, respectively, according to XRD tests. The samples cooled at lower cooling rates had superior combination of strength and ductility, due to the larger amount of retained austenite [28-30]. These results suggested that lower cooling rates provided adequate time for carbon partitioning and larger amount of retained austenite was obtained in microstructures. Furthermore, martensite transformation of retained austenite during tensile deformation enhanced the work hardening ability and increased the combination of strength and ductility [31].

\subsection{Effect of Cooling Rates on Work Hardening Behavior}

At small strain after yielding, the work hardening behavior reflected the extent of dislocations interaction in microstructures prior to the occurrence of TRIP effect. In Fig. 10c, the sample cooled at $5{ }^{\circ} \mathrm{C} / \mathrm{s}$ has higher instantaneous work hardening exponent during dislocations interaction stage in contrast to the samples cooled at $0.05{ }^{\circ} \mathrm{C} / \mathrm{s}$ and $0.5{ }^{\circ} \mathrm{C} / \mathrm{s}$. The samples cooled at lower cooling rates had relatively lower instantaneous work hardening exponent during dislocations interaction stage, due to the presence of bainitic ferrite and retained austenite in microstructures. On contrary, the sample cooled at higher cooling rates had higher instantaneous work hardening exponent during dislocations interaction stage, due to the existence of martensite with high-density dislocations in microstructures. The higher cooling rate retained majority of dislocations in microstructures and made residual austenite directly transform into martensite. Furthermore, the high-density dislocations in martensite increased instantaneous work hardening exponent at small strain after yielding. It was indicated that the work hardening behavior before the occurrence of TRIP effect had relationship with the extent of dislocations interaction. As a result, the sample cooled at higher cooling rates had higher instantaneous work hardening exponent than that cooled at lower cooling rates during dislocations interaction.

The work hardening behavior was determined by the volume fraction of retained austenite and its stability, which was associated with the cooling rate. In Fig. 10d, from instantaneous work hardening exponent at different cooling rates, the work hardening behavior of the experimental steel has significant differences. The instantaneous work hardening exponent of the sample cooled at $0.05{ }^{\circ} \mathrm{C} / \mathrm{s}$ increased continuously until it reached the maximum value of 0.2 at true strain of 0.18 , while the instantaneous work hardening exponent of the sample cooled at $0.5^{\circ} \mathrm{C} / \mathrm{s}$ remained stable during plastic deformation stage. Compared with the samples cooled at lower cooling rates, the instantaneous work hardening exponent of the sample cooled at $5{ }^{\circ} \mathrm{C} / \mathrm{s}$ decreased rapidly during plastic deformation. The samples cooled at lower cooling rates exhibited better work hardening ability in contrast to that cooled at higher cooling rates, for the reason that retained austenite in the samples cooled at lower cooling rates experienced continuous transformation during plastic deformation and smaller amount of retained austenite was available in the sample cooled at higher cooling rates [32].

The stability of retained austenite was affected by many factors, such as carbon content, grain size, grain morphology 
and surrounding phases. De Knijf et al. [33] indicated that crystallographic orientation also had effects on the stability of retained austenite. The influence of crystallographic orientation on transformation is ascribed to the orientation-dependent mechanical driving force. During tensile deformation, retained austenite with higher driving force transformed into martensite preferentially. As for the work hardening behavior, carbon content and grain morphology were the critical factors discussed for the stability of retained austenite in this research.

According to SEM observations and XRD tests, different types and amounts of retained austenite were obtained in the samples cooled at different cooling rates. The samples cooled at lower cooling rates mainly contained film-like and blocky retained austenite with a large amount, whereas the sample cooled at higher cooling rates contained a small amount of blocky retained austenite. In particular, the sample cooled at $0.05^{\circ} \mathrm{C} / \mathrm{s}$ had larger amount of retained austenite of $18.48 \%$ compared with the sample cooled at $0.5{ }^{\circ} \mathrm{C} / \mathrm{s}$ with smaller amount of $15.77 \%$. Furthermore, retained austenite in the sample cooled at $0.05^{\circ} \mathrm{C} / \mathrm{s}$ was likely to be more stable, because the slower cooling rate encouraged carbon partitioning in retained austenite. Some studies showed that film-like retained austenite was more stable owing to its higher carbon content and it tended to transform at large strain, whereas blocky retained austenite was less stable due to its larger grain size and it tended to transform at small strain [22, 23]. In the sample cooled at $0.05^{\circ} \mathrm{C} / \mathrm{s}$, film-like retained austenite with higher stability played major roles in TRIP effect; thus, the instantaneous work hardening exponent increased continuously. In the sample cooled at $0.5{ }^{\circ} \mathrm{C} / \mathrm{s}$, film-like and blocky retained austenite provided TRIP effect together, so the instantaneous work hardening exponent remained stable. Besides, in the sample cooled at $5{ }^{\circ} \mathrm{C} / \mathrm{s}$, little retained austenite made contribution to TRIP effect; therefore, the instantaneous work hardening exponent decreased rapidly. These results suggested that the samples cooled at different cooling rates showed different work hardening behaviors, which depended on the volume fraction and stability of retained austenite. It was indicated that the work hardening behavior during the occurrence of TRIP effect was associated with the ability of dislocations increment. As a consequence, the samples cooled at lower cooling rates had continuous work hardening behavior and exhibited excellent combination of strength and ductility.

In this research, the cooling rate had significant effects on microstructures of the experimental steel, especially the volume fraction and stability of retained austenite. The volume fraction of retained austenite and its stability determined the work hardening behavior, which was important for the mechanical properties of the experimental steel. When the samples were cooled at lower cooling rates, two types of retained austenite were present in microstructures and adequate time was available for carbon partitioning, which resulted in excellent combination of strength and ductility. The cooling rate less than $1{ }^{\circ} \mathrm{C} / \mathrm{s}$ met the kinetic requirements for the stability of retained austenite, whereas the cooling rate in coiling process was always less than $0.1{ }^{\circ} \mathrm{C} / \mathrm{s}$ in practice. It was proposed that the cooling rate less than $1{ }^{\circ} \mathrm{C} / \mathrm{s}$ from bainite transformation temperature of $400{ }^{\circ} \mathrm{C}$ was an appropriate process window of practical production for hot-rolled TRIP steels.

\section{Conclusions}

The effect of cooling rates in coiling process on microstructures and mechanical properties in Al-bearing hot-rolled TRIP steel was investigated. Microstructures characterizations, mechanical properties and work hardening behavior were elucidated. The conclusions are summarized as follows.

1. The microstructures consisted of polygonal ferrite, bainitic ferrite and retained austenite at $0.05-1{ }^{\circ} \mathrm{C} / \mathrm{s}$, while bainitic ferrite and retained austenite were substituted by martensite at $5-10{ }^{\circ} \mathrm{C} / \mathrm{s}$, because higher cooling rates promoted the formation of martensite. With the increase in cooling rates, film-like retained austenite disappeared at higher cooling rates due to insufficient carbon partitioning and only blocky retained austenite was remained. The volume fraction of retained austenite was $9-11 \%$ at cooling rates of $0.05-1{ }^{\circ} \mathrm{C} / \mathrm{s}$ and $4-6 \%$ at cooling rates of $5-10{ }^{\circ} \mathrm{C} / \mathrm{s}$. In addition, martensite/austenite island was observed owing to the heterogeneous carbon distribution.

2. The hardness of experimental steel changed in the range of $260-290 \mathrm{HV}$ at $0.05-1{ }^{\circ} \mathrm{C} / \mathrm{s}$, whereas the hardness was significantly increased to $320-360 \mathrm{HV}$ at $5-10{ }^{\circ} \mathrm{C} / \mathrm{s}$, because of the formation of martensite. The samples cooled at $0.05^{\circ} \mathrm{C} / \mathrm{s}$ and $0.5^{\circ} \mathrm{C} / \mathrm{s}$ exhibited excellent mechanical properties, with tensile strength of $712 \mathrm{MPa}$ and $726 \mathrm{MPa}$, total elongations of 42 and $36 \%$ and strength ductility balances of $29.91 \mathrm{GPa} \%$ and $26.15 \mathrm{GPa} \%$, respectively. In comparison, the sample cooled at $5{ }^{\circ} \mathrm{C} / \mathrm{s}$ exhibited different mechanical properties, with tensile strength of $832 \mathrm{MPa}$, total elongation of $24 \%$ and strength ductility balance of $19.96 \mathrm{GPa} \%$.

3. During dislocations interaction, the sample cooled at $5{ }^{\circ} \mathrm{C} / \mathrm{s}$ had higher instantaneous work hardening exponent. During plastic deformation, the instantaneous work hardening exponent of the sample cooled at $0.05{ }^{\circ} \mathrm{C} / \mathrm{s}$ increased continuously until it reached the maximum value, while the instantaneous work hardening exponent of the sample cooled at $0.5^{\circ} \mathrm{C} / \mathrm{s}$ remained stable. In conclusion, due to the larger amount of retained austenite with higher stability, the samples cooled at lower cool- 
ing rates had continuous work hardening behavior and exhibited excellent combination of strength and ductility.

Acknowledgements The authors acknowledge the support from the National Natural Science Foundation of China (No. 51504063). R.D.K. Misra also acknowledges for continued collaboration with Northeastern University as an honorary professor by providing guidance to students in research.

\section{References}

[1] C. Wang, H. Ding, M. Cai, B. Rolfe, Mater. Sci. Eng. A 610, 65 (2014)

[2] M. De Meyer, B.C. De Cooman, D. Vanderschueren, Iron Steelmak. 27, 55 (2000)

[3] J. Mahieu, B.C. De Cooman, J. Maki, S. Claessens, Iron Steelmak. 29, 29 (2002)

[4] B. Mintz, Int. Mater. Rev. 46, 169 (2001)

[5] K. Zhu, C. Mager, M. Huang, J. Mater. Sci. Technol. 33, 12 (2017)

[6] V.S.Y. Injeti, Z.C. Li, B. Yu, R.D.K. Misra, Z.H. Cai, H. Ding, J. Mater. Sci. Technol. 34, 745 (2018)

[7] H.Q. Huang, H.S. Di, N. Yan, J.C. Zhang, Y.G. Deng, R.D.K. Misra, J.P. Li, Acta Metall. Sin. (Engl. Lett.) 31, 503 (2018)

[8] P.J. Jacques, E. Girault, A. Mertens, B. Verlinden, J. Van Humbeeck, F. Delannay, ISIJ Int. 41, 1068 (2001)

[9] D.W. Suh, S.J. Park, C.S. Oh, S.J. Kim, Scr. Mater. 57, 1097 (2007)

[10] J. Mahieu, B.C. De Cooman, J. Maki, Metall. Mater. Trans. A 33, $2573(2002)$

[11] Y.J. Li, J. Kang, W.N. Zhang, D. Liu, X.H. Wang, G. Yuan, Mater. Sci. Eng. A 710, 181 (2018)

[12] J. Chiang, J.D. Boyd, A.K. Pilkey, Mater. Sci. Eng. A 638, 132 (2015)
[13] J. Chiang, B. Lawrence, J.D. Boyd, A.K. Pilkey, Mater. Sci. Eng. A 528, $4516(2011)$

[14] A.Z. Hanzaki, R. Pandi, P.D. Hodgson, S. Yue, Metall. Mater. Trans. A 24, 2657 (1993)

[15] S.M.K. Hosseini, A.Z. Hanzaki, M.J.Y. Panah, Mater. Sci. Eng. A 374, 122 (2004)

[16] H.S. Wang, J. Kang, W.X. Dou, Y.X. Zhang, G. Yuan, G.M. Cao, R.D.K. Misra, G.D. Wang, Mater. Sci. Eng. A 702, 350 (2017)

[17] N.H.V. Dijk, A.M. But, L. Zhao, J. Sietsma, S.E. Offerman, J.P. Wright, Acta Mater. 53, 5439 (2005)

[18] D.J. Dyson, B. Holmes, ISIJ Int. 208, 469 (1970)

[19] J.H. Hollomon, J. Member, Metall. Technol. 12, 268 (1945)

[20] F.H. Akbary, J. Sietsma, G. Miyamoto, T. Furuhara, M.J. Santofimia, Acta Mater. 104, 72 (2016)

[21] Z.Q. Liu, G. Miyamoto, Z.G. Yang, T. Furuhara, Acta Mater. 61, $3120(2013)$

[22] X.C. Xiong, B. Chen, M.X. Huang, Scr. Mater. 68, 321 (2013)

[23] Y.J. Li, D. Chen, X.L. Li, Steel Res. Int. 88, 11 (2017)

[24] C. Wang, X. Wu, J. Liu, N. Xu, Mater. Sci. Eng. A 438, 267 (2006)

[25] E.J. Seo, L. Cho, Y. Estrin, B.C. De Cooman, Acta Mater. 113, 124 (2016)

[26] G.A. Thomas, J.G. Speer, D.K. Matlock, Metall. Mater. Trans. A 42A, 3652 (2011)

[27] J. Zhao, W. Hu, X. Wang, J. Kang, G. Yuan, H. Di, R.D.K. Misra, Mater. Sci. Eng. A 666, 214 (2016)

[28] A. Mertens, E.M. Bellhouse, J.R. Mcdermid, Mater. Sci. Eng. A 608, 249 (2014)

[29] E.M. Bellhouse, J.R. Mcdermid, Metall. Mater. Trans. A 41, 1460 (2010)

[30] J.R. Mcdermid, H.S. Zurob, Y. Bian, Metall. Mater. Trans. A 42, 3627 (2011)

[31] E. Pereloma, H. Beladi, L. Zhang, I. Timokhina, Metall. Mater. Trans. A 43, 3958 (2012)

[32] L. Li, X. Zhang, W. Yang, Metall. Mater. Trans. A 44, 4337 (2013)

[33] D. De Knijf, T. Nguyen-minh, R.H. Petrov, L.A.I. Kestens, J.J. Jonas, J. Appl. Cryst. 47, 1261 (2014) 